\title{
PAULO FREIRE: CONTRAPONTOS AO DISCURSO NEOCONSERVADOR
}

\author{
PAULO FREIRE: COUNTERPOINTS TO THE NEOCONSERVATIVE DISCOURSE
}

\author{
José Nogueira da Silva \\ Doutor em Educação \\ Universidade Federal de Alagoas - Ufal \\ Maceió, Alagoas - Brasil \\ jose.nogueira@cedu.ufal.br \\ Adriana Cavalcanti dos Santos \\ Doutora em Educação \\ Universidade Federal de Alagoas - Ufal \\ Maceió, Alagoas - Brasil \\ adricavalcanty@hotmail.com \\ Inalda Maria dos Santos \\ Doutora em Educação \\ Universidade Federal de Alagoas - Ufal \\ Maceió, Alagoas - Brasil \\ inalda.santos@cedu.ufal.br
}

Resumo: O artigo se constrói no entrelaçamento dos contrapontos entre o discurso neoconservador e os princípios defendidos por Freire (2018) sobre liberdade e de formação humana. Os resultados mostram que ambos os discursos possuem finalidades distintas, principalmente na concepção de liberdade, uma vez que a liberdade de concorrência econômica e para consumo foi preponderante na teoria e nos governos declaradamente neoliberais, enquanto a liberdade na educação freiriana defende a consciência de si no mundo para permitir uma constante busca por ser mais. Nesses termos, é necessária a consciência dos entraves do capitalismo e suas ações neoliberais que, contraditoriamente, impedem as ações do sujeito como agente livre.

Palavras-chave: capitalismo; liberdade; neoliberalismo.

Abstract: This paper is built on the intertwining of the counterpoints between the neoconservative discourse and the freedom and human formation principles defended by Freire (2018). The results show us that both discourses have different purposes, especially when we are talking about the conception of freedom, since the freedom of economic competition and its consumption was predominant in the neoliberal theory and in self-proclaimed neoliberal governments, and, on the other hand, the freedom in the Freirean education defends the self-consciousness in the world to allow a constant quest to be more. In these terms, it is necessary to be aware of the obstacles of capitalism and its neoliberal attitudes that, contradictorily, prevent the actions of the subject as a free agent.

Keywords: capitalismo; freedom; neoliberalism.

\section{Para citar - (ABNT NBR 6023:2018)}

SILVA, José Nogueira da; SANTOS, Adriana Cavalcanti dos; SANTOS, Inalda Maria dos. Paulo Freire: contrapontos ao discurso neoconservador. Eccos - Revista Científica, São Paulo, n. 59, p. 1-21, e15807, out./dez. 2021. Disponível em: https://doi.org/10.5585/eccos.n59.15807. 


\section{Introdução}

Nos últimos anos, o mundo contemporâneo vem sofrendo os impactos do desmonte político-econômico da onda neoconservadora (VILLARREAL, 1984). Essa onda reforça ainda os princípios de um código moral e de uma estrutura social tradicional, influenciando as relações humanas em todas as instâncias da sociedade, com destaque no campo educacional.

Enquanto voz de resistência, representando e defendendo os excluídos, Paulo Freire (2018) vem, desde a década de sessenta do século passado, denunciando as ideologias conservadoras e às práticas pedagógicas excludentes. Assim, nesse artigo, demarcamos a atualidade do pensamento de Freire assente uma dimensão renovada, na qual sua pedagogia ganha mais evidência e destaque no confronto com os ideais da onda neoconservadora. Segundo Freire (1981, p. 38-39),

Há algo ainda implícito na ideologia das classes dominantes e que análise de cartilhas e livros de leitura revela - o perfil dos analfabetos como seres marginais. Aqueles que consideram os analfabetos como seres marginais devem, porém, reconhecer a existência de uma realidade de que eles se encontram marginalizados - realidade que não é apenas um espaço físico, mas econômico, histórico, social, cultural. Desta maneira, os analfabetos têm de ser reconhecidos como seres "fora de" ou "marginais a" alguma coisa, pois que seria impossível estarem marginais a nada. Mas estar "fora de" implica em que, quem se encontra "ora de" fez um movimento do centro onde se achava para a periferia. Admitindo a existência de homens e mulheres "fora de", marginais à estrutura da sociedade, parece legítimo perguntar: quem é o autor deste movimento? Será que os chamados marginais, entre eles os analfabetos, tornam a decisão de mover-se até a "periferia" da sociedade? Se assim é, a marginalidade é uma opção, com tudo que ela envolve: fome, doença, raquitismo, baixos índices de expectativa de vida, crime, promiscuidade, morte em vida, impossibilidade de ser, desesperança.

Partindo desses pressupostos, o artigo tem por objetivo discutir os contrapontos entre o discurso neoconservador construído historicamente e os princípios defendidos por Freire (2018) sobre liberdade e de formação humana. Para isso, foram selecionadas duas obras clássicas que permitem inferir os referidos contrapontos; Pedagogia do Oprimido, de Paulo Freire (2018) e O Caminho da Servidão, de Friedrich Hayek (2010).

É no cenário dessas problemáticas que o artigo traça ponderações sobre o neoliberalismo; os argumentos voltados para uma perspectiva emancipatória adotados no livro "Pedagogia do Oprimido" (FREIRE, 2018); e os desencontros dos conceitos de liberdade, defendidos pela onda neoconservadora por autores como Mises (2010) e Hayek (2010). 


\section{Trajetória do neoliberalismo: ponderações}

O neoliberalismo como proposta política de Estado ganha notoriedade no contexto pósII Guerra Mundial, quando a divisão de países entre blocos capitalistas e socialistas gerou o que hoje chamamos de Guerra Fria. Pouco antes, a obra $O$ Caminho da Servidão, de Friedrich Auguste Hayek, foi publicada na Grã-Bretanha em 1944, considerada uma pedra angular para a disseminação da ideologia neoliberal (MATOS, 2008, p. 194).

O livro de Hayek (2010), supramencionado, efetua violentas críticas à intervenção do Estado no mercado econômico. Este caracterizado como uma ameaça à liberdade de expressão econômica e política. Essa prática poderia culminar com imposições de medidas administrativas, como o desmantelamento do Estado de Direito e o surgimento de um Estado totalitário (HAYEK, 2010; HARVEY, 2008).

Entendemos como Estado totalitário o conceito definido por Arendt (1989, p. 375) como "a dominação permanente de todos os indivíduos em toda e qualquer esfera da vida" (ARENDT, 1989, p. 375), assim, alguns conceitos presentes do contexto da época e trazendo ideologias distintas como: O Nazismo na Alemanha com Adolf Hitler, o Fascismo com Benito Mussolini na Itália, Oliveira Salazar em Portugal e o Stalinismo na União Soviética com Joseph Stalin. Esses exemplos mostram propostas de governos distintas, mas com um ponto em comum; Estados totalitários temidos pelos seus erros, principalmente depois dos horrores da Segunda Guerra Mundial. As propostas desses distintos governos com isso surgiram propostas econômicas opostamente radicais no que concerne à presença do Estado na liberdade das pessoas, apesar de também serem totalitaristas na delimitação de Hannah Arendt (1989). Para Villarreal (1984, p. 494),

\footnotetext{
A história e a experiência recente da América Latina, porém, são muito claras. O liberalismo econômico, longe de promover o liberalismo político, gera e requer para sua implementação um totalitarismo político que dá lugar a um novo modelo: $\mathrm{O}$ NEOLIBERALISMO AUTORITÁRIO.
}

Segundo Matos (2008), o Partido Trabalhista inglês era o principal alvo das críticas naquele momento, uma vez que a eleição geral de 1945 se aproximava. Em 1947, Hayek juntamente com outros dois simpatizantes do neoliberalismo, Karl Popper e Ludwing Von Mises, fundam um grupo destinado à promoção da ideologia do livre mercado, intitulado Mon Pèlerin Society, nome justificado pela reunião ter ocorrido na estação de Mont Pèlerin na Suíça (MATOS, 2008).

Até o início da década de 1970, "as ideias neoliberais não obtiveram grande difusão" (MATOS, 2008, p. 194), uma vez que os Estados Unidos e as grandes potências europeias 
estavam em um momento de crescimento econômico. Segundo Vilarreal (1984), entre 1967 e 1973, o crescimento anual da França ficou numa média de 5,6 e os Estados Unidos 3,5, ou seja, o ambiente não estava favorável para uma proposta do fim do Estado, pois os Estados/Nações estavam reconstruindo o mundo pós-guerra. No entanto, depois de 1973, os países de capitalismo avançado entraram em recessão, fruto de taxas baixas de crescimento e altas de inflação. Com isso, os argumentos neoliberais ganharam espaço, com críticas aos sindicatos e ao movimento operário, alegando que essas instâncias teriam deteriorado as bases de acumulação do capital, pois reivindicaram salários mais altos e exigiram que o Estado expandisse os gastos sociais.

Após esse marco histórico, o neoliberalismo ficou cada vez mais atraente, principalmente nos Estados Unidos e na Grã-Bretanha, além de uma influência acadêmica em ascensão, com destaque para a Universidade de Chicago. A respeitabilidade acadêmica foi conquistada de vez com Hayek em 1974, e Milton Friedman em 1976, ambos os intelectuais vencedores do prêmio Nobel de economia (HARVEY, 2008).

Em suma, a proposta neoliberal envolvia a manutenção de um Estado forte o suficiente para diminuir o poder dos sindicatos, ter controle monetário, depois disso teria liberdade para diminuir os gastos sociais e interferir o mínimo possível na economia. No entanto, continuaria com influência em meios influentes como a educação. Tal influência ajudaria a criar um grupo de reserva de trabalhadores capacitados. Paralelo a isso, realizaria reformas fiscais estimuladores dos agentes econômicos, na prática seria a redução de impostos sobre os altos rendimentos e rendas (MATOS, 2008). Mesmo assim, foi necessário cerca de uma década para que um governo com um programa neoliberal de um país capitalista avançado chegasse ao poder, isso em 1979 com Margareth Teatcher, na Inglaterra. Pouco depois, Ronald Reagan, em 1980, nos Estados Unidos, Khol, em 1982, na Alemanha Ocidental, Schluter, em 1983, na Dinamarca. Enfim, com exceção da Suécia e Áustria, os países do norte da Europa Ocidental elegeram chefes de Estado neoliberais, o que resultou em mudanças radicais nas relações entre o povo e o Estado.

Em seu governo, Thatcher colocou em prática as propostas teorizadas por Hayek (2010), entre elas: "contração monetária, elevação das taxas de juros, diminuição dos impostos sobre os rendimentos altos, abolição dos controles sobre os fluxos financeiros, aumentos dos níveis de desemprego, repressão a greves (em especial o movimento mineiro)" (MATOS, 2008, p. 196). Somado a isso, o neoliberalismo impôs uma legislação desvantajosa para os sindicatos, além de um programa radical de privatização. 
No caso de Reagan, pela falta de um Estado de bem-estar comparado ao Europeu, deu enfoque à corrida militar com a União Soviética, além de reduzir os impostos em favor das classes mais abastadas, elevar a taxa de juros e reprimir greves, como no setor da aviação civil. Essa corrida armamentista gerou um déficit público gigantesco (MATOS, 2008).

Cada país capitalista implantou o neoliberalismo de acordo com as conveniências ideológicas já existentes, alguns mais cautelosos, enfatizando a disciplina orçamentária e reformas fiscais, mas sem realizar cortes sociais ou reprimir os sindicatos, outros, foram mais fiéis ao programa e abandonaram de vez o objetivo de pleno emprego, privatizaram suas maiores estatais e reprimiram fortemente os protestos civis, para isso, investiram no setor militar.

Para compreendermos o crescimento e implantação dessas políticas, é necessário perceber a articulação entre o político e o econômico, simultaneamente. A mercantilização de serviços públicos, por exemplo, foi possível graças a intervenções políticas vindas de medidas econômicas tomadas pelas políticas de Estado. Em cada região, o capitalismo neoliberal avançou perante as liberdades concedidas pelo contexto de cada local.

No caso da América do Sul, os meios não foram democráticos naquele momento:

Como se instaurou a neoliberalização e quem o fez? A resposta em países como Chile e a Argentina nos anos 70 foi tão simples quanto rápida, brutal e segura: um golpe militar apoiado pelas classes altas tradicionais (assim como pelo governo norteamericano) seguido pela cruel repressão de todas as solidariedades criadas no âmbito dos movimentos trabalhistas e sócias urbanos que tanto ameaçavam seu poder. Mas a revolução neoliberal que se costume atribuir a Thatcher e Reagan a partir de 1979 tinha de ser instaurada por meios democráticos. A ocorrência de uma mudança de tamanha magnitude exigia que se construísse antes o consentimento político num espectro suficiente amplo da população para que se ganhasse as eleições (HARVEY, 2008, p. 49).

A década de 80 mostrou que as políticas governamentais implantadas, ao menos em países de capitalismo avançado, conseguiam controlar a inflação e recuperar a taxa de lucro das empresas, já que o enfraquecimento do movimento sindical, e o crescimento das taxas de desemprego e perda de direitos trabalhistas criou um ambiente favorável para contratações com um bom exército industrial de reserva. Porém, o crescimento estável da economia não foi mais possível, uma vez que a desregulamentação financeira gerou condições mais vantajosas para a inversão especulativa do que produtiva.

Nesse movimentum histórico, em 1991, os países capitalistas enfrentaram uma nova crise econômica com profunda recessão devido ao crescimento da dívida pública dos países ocidentais, endividamento privado das famílias e empresas sem precedentes no período pósguerra (MATOS, 2008). Com isso, a instabilidade econômica tem sido cada vez mais efêmera. 
Com isso, é válido perguntarmos: a quem interessa essas políticas neoliberais? Cerqueira (2008) propõe responder ao afirmar que as multinacionais são as mais beneficiadas, isso porque buscou fusões e integrações entre empresas que isoladamente já se mostram fortes em seus setores. Essas junções a tornam mais fortes, posto que as possibilidades de lucro crescem. Pois, como os grandes grupos têm sua origem em países do mundo economicamente desenvolvido, acabam sendo os mais beneficiados.

Infelizmente, houve e há prejudicados nesse processo, exatamente os protagonistas citados por Paulo Freire em Pedagogia do Oprimido (2018); “os trabalhadores desempregados e os países que não são desenvolvidos" (CERQUEIRA, 2008, p. 186). Uma massa de civis que perderam direitos conquistados ao longo de décadas, visto que a pressão de multinacionais com respaldo dos governos de países desenvolvidos possibilita a derrubada de barreiras protecionistas sob a alegação de uma suposta liberdade do mercado de países subdesenvolvidos em caminho ao desenvolvimento, contudo, a concorrência desleal aumenta a desigualdade entre as economias.

Ao fim da década de 1980 e início de 1990, os pressupostos neoliberais foram condensados no "Consenso de Washington". Esse termo do economista John Williamson foi resultado de um encontro em 1989, na cidade de Washington. Participaram do encontro funcionários do governo dos EUA e de órgãos financeiros como o FMI, Banco Mundial e BID, além de uma plêiade de economistas latino-americanos. O documento produzido nesse encontro traz recomendações de status liberalizante na economista, como; disciplina fiscal, prioridade em gastos públicos para a saúde, educação e infraestrutura, reforma fiscal, taxas de câmbio unificadas, liberalização comercial e de investimento externo, privatização, desregulamento do mercado e proteção de direitos de propriedade (MATOS, 2008)

As orientações deixam clara a natureza neoliberal das propostas. As mesmas visam ajustar o mercado para a nova fase do capitalismo, na qual as fronteiras do mercado seriam extintas em prol de uma sociedade unificada por meio do livre mercado. Essa unificação não se daria apenas no âmbito econômico, mas também cultural com auxílio das tecnologias de comunicação. Nesse ínterim, pensadores pertencentes e/ou simpatizantes com os setores prejudicados nesse processo refletiram maneiras de burlar essas imposições políticas, conscientizar as populações das medidas tomadas e mobilizar as massas, Paulo Freire está entre eles. Nesse contexto, Freire (2018) propõe táticas "dentro do campo do inimigo" (CERTEAU, 1998) perante as estratégias do Estado neoliberal. Certeau (1998, p. 100) define por tática: 
a ação calculada que é determinada pela ausência de um próprio. Então nenhuma delimitação de fora lhe fornece a condição de autonomia. A tática não tem por lugar senão o do outro. E por isso deve jogar com o terreno que lhe é imposto tal como se organiza a lei de uma força estranha. Não tem meios para se manter em si mesma, à distância, numa posição recuada, de previsão e de convocação própria: a tática é movimento "dentro do campo do inimigo", como dizia von Büllow, e no espaço por ele controlado.

\section{Influências externas nas orientações da política educacional brasileira}

As orientações neoliberais, presentes na filosofia de ação de vários países, partem das premissas da reestruturação econômica, que se define como um conjunto de programas e políticas que sofrem as orientações do Banco Mundial, do Fundo Monetário Internacional (FMI) e de outras organizações financeiras. Conforme Torres (1995, p. 115-116), essas premissas implicam:

[...] redução do gasto público; redução dos programas que são considerados gasto público e não investimento; venda das empresas estatais, parestatais ou de participação estatal; e mecanismos de desregulamentação para evitar o intervencionismo estatal no mundo dos negócios. Junto com isso, propõe-se a diminuição da participação financeira do estado no fornecimento de serviços sociais (incluindo educação, saúde, pensões e aposentadorias, transporte público e habitações populares e sua subsequiente transferência ao setor privado (privatização). A noção de privado (e as privatizações) são glorificadas como parte de um mercado livre, com total confiança na eficiência da competição, onde as atividades do setor público ou estatal são vistas como ineficientes, improdutivas, anti-econômicas e como um desperdício social, enquanto o setor privado é visto como eficiente, efetivo, produtivo, podendo responder, por sua natureza menos burocrática, com maior rapidez e presteza às transformações que ocorrem no mundo moderno".

Em tal contexto, o modelo de desenvolvimento perseguido pelo Banco Mundial vem privilegiando quatro princípios de ação para a área da educação, os quais devem ser adotados pelos países que recebem financiamentos, independente de suas especificidades históricas e culturais. São eles: priorização de investimentos na educação primária, a partir da crença de que as taxas de retorno, nesse nível, são, significativamente, maiores do que as dos demais níveis educacionais; mudanças na gestão, a partir da descentralização administrativa, com base no pressuposto de que os programas administrados localmente são mais econômicos; priorização de investimentos na formação geral, por considerar que, a longo prazo, ela é mais produtiva do que a educação vocacional; recuperação de custos de investimentos e eficiência no manejo dos recursos, para evitar desperdícios (PLANK, 1991 apud TORRES, 1995). Para Torres (1995, p. 130), não apenas o Banco Mundial como também, todos os organismos internacionais de financiamento acabam por exercer um papel neocolonial quando instituem as normas e políticas, de caráter homogêneo e universal, para definir os "problemas e as soluções viáveis e legítimas no contexto da internacionalização e globalização do capitalismo" ( p. 130). 
Discursando sobre a problemática do neoliberalismo na educação, Celestino Júnior (1996), argumenta que tal como as ideologias de conveniência, a ideologia da incompetência cumpre a função de desinteressar a relação entre os indivíduos e o estado como provedor dos demandas da população. Nesse sentido, a ideologia da incompetência diz respeito ao que se convencionou chamar de "neoliberalismo", e essa por sua vez, refere-se à ideologia da flexibilização que, por seu turno:

[...] cumpre a função primordial de preparar o terreno para a supressão de garantias
institucionais e constitucionais destinadas ao exercício de direitos consagrados pelas
lutas históricas dos trabalhadores e de toda a humanidade. Em nome da 'globalização'
- outra ideologia - e da 'nova qualificação para o trabalho' - ainda outra ideologia -
flexibilizar significa desempregar e administrar significa desestabilizar. Produzir pode
significar simplesmente, 'terceirizar' (CELESTINO JÚNIOR, 1996, p. 75-76).

Gentili (1998) adverte que a reforma educacional brasileira dos anos 90, se pautou em duas lógicas: uma consiste na centralização do controle pedagógico, e outra, na descentralização dos mecanismos de financiamento e gestão do sistema.

Neste contexto, nos chama atenção diante do quadro da reforma educacional, as mudanças no padrão de financiamento da educação mediante os sistemas de descentralização e sua transferência para os municípios, por um lado, e por outro, o destaque dos organismos financeiros internacionais no planejamento e implementação de políticas sociais nos países da América Latina, em particular, o FMI e o Banco Mundial.

Assim, a compreensão dos impactos do Consenso de Washington na condução de políticas educacionais é fundamental, para que possamos compreender as mudanças ocorridas na dinâmica da escola pública.

Nessa perspectiva, a reflexão acerca das mudanças que vem ocorrendo com a implementação do novo padrão de gestão e de financiamento é pertinente, visto que, no campo da literatura educacional, estudiosos vem se dedicando a problematizar a questão da privatização das políticas e dos seus efeitos em relação ao usufruto por todos do direito à educação pública.

Para Gentili (1998), a característica fundamental deste processo é o progressivo desmantelamento do Estado em seu papel de produtor de bens e serviços e ainda como aparelho institucional voltado para a garantia e promoção dos direitos de cidadania, com base nas orientações de cunho neoliberal. Entretanto, a dinâmica da privatização, mesmo constituindo uma estratégia global da reestruturação capitalista, assume conotações diferentes que variam de acordo com o contexto específico de cada atividade em processo de transferência ao setor privado. 
Neste sentido Torres (1995), afirma a necessidade de uma explicação sobre o sentido das políticas de privatização que vem orientando as reformas daqueles países presentes no Consenso de Washington. Assim, argumenta que essas reformas orientadas para impulsionar o mercado, constituem numa estratégia de ação das políticas neoliberais; pois, por um lado, “mediante a privatização de empresas do setor público, reduz-se a pressão sobre o gasto fiscal. Por outro, a privatização constitui um instrumento muito apropriado para despolitizar as práticas regulatórias do estado nas áreas de formação de políticas públicas” (TORRES, 1995 p. 125).

Após um panorama do estabelecimento e das consequências do neoliberalismo não só na Europa, mas a nível mundial, é pertinente minuciarmos a proposta em si e realizarmos uma analogia com a Pedagogia do Oprimido, de Paulo Freire (2018), assim teremos uma melhor compreensão das duas propostas nos planos político, econômico e educacional, e, dessa maneira, compreenderemos melhor como elas se cruzam e divergem em determinados momentos, especificamente no conceito de liberdade, que será abordado na seção final.

\section{A Pedagogia do Oprimido no caminho da servidão}

Em sua obra, Hayek (2010) realiza críticas violentas à planificação da economia, ou seja, um procedimento econômico regido pelo Estado, com metas e objetivos determinados e forte poder de intervenção no mercado. A premissa defendida é de que o planejamento econômico resulta inevitavelmente em regimes totalitários, uma vez que o mundo tinha passado por experiências recentes de totalitarismos, a exemplo da Itália com Benito Mussolini, Alemanha com Adolf Hitler e a União Soviética com Josef Stalin, inclusive o início do capítulo 4 do livro, intitulado: “A 'Inevitabilidade' da Planificação", é iniciado com uma frase de Mussolini: "Fomos os primeiros a afirmar que, quanto mais complexa se torna a civilização,

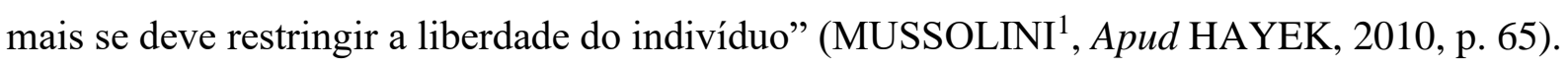
Essa premissa sinaliza a relação que a retórica neoliberal faz entre a presença do Estado na liberdade das pessoas e os regimes totalitários, algo reafirmado diversas vezes no decorrer da obra, conjuntamente com a conciliação de regimes totalitários e, portanto, estatais ideologicamente distintos. Segundo Hayek (2010, p. 118),

${ }^{1}$ Frase presente na epígrafe da obra supracitada de Hayek (2010). 
Há, todavia, duas distinções fundamentais a fazer. Em primeiro lugar, é possível tomar medidas concretas sem saber de que modo elas atingirão cada indivíduo e, portanto, sem visar a tais efeitos específicos. Já discutimos esse ponto. Em segundo lugar, é a amplitude das atividades governamentais que determina se tudo o que um indivíduo recebe em qualquer ocasião depende do governo, ou se a influência deste se limita a condicionar se certas pessoas receberão certas coisas, de certo modo, em certas ocasiões. Nisto consiste toda a diferença entre um sistema livre e um sistema totalitário. O contraste entre a sociedade liberal e a sociedade totalmente planificada fica patente nos ataques movidos por nazistas e socialistas à "separação artificial da economia e da política" e na sua exigência de que a política domine a economia. (Grifo do autor)

O temor pós-guerra com regimes totalitários foi explorado na retórica neoliberal. Para Hayek (2010, p. 110), nos estados totalitários "as necessidades da população seriam atendidas em momentos determinados por outrem, nesse caso o estado, que decidiria o momento ideal para isso". No entendimento do autor, a estatização da economia priva os indivíduos da liberdade de escolha e dá a população o que melhor se ajusta aos planos econômicos do estado e não às necessidades individuais. Corroborando com esse raciocínio, Matos (2008, p. 199) aponta que "as instituições políticas características do Estado de Bem-Estar progressivamente corroeriam as tradições de liberdade política características da sociedade inglesa por meio de uma 'transformação de ordem psicológica' do povo", a causa seria a ascensão do liberalismo e as transformações que causou na sociedade, uma vez que certas condições de vida não se tornaram mais aceitáveis.

$\mathrm{Na}$ visão dos autores supratranscritos, o entendimento equivocado da opinião pública resulta na passagem de uma "sociedade livre" para uma sociedade socialista totalitária, compreensão que revela a descrença dos liberais nas atitudes das massas. Essa convergência de ideias enxerga nos civis não pertencentes à elite uma inabilidade para raciocinar de maneira lógica, uma vez que os imediatismos das políticas do Estado fazem com que prefiram "privilégios" efêmeros a ganhos sociais duradouros. Para Hayek (2010, p. 130),

É fácil demonstrar que a garantia de uma renda invariável só poderá ser concedida a todos pela abolição total da liberdade de escolha da profissão. E contudo, embora essa garantia geral de expectativas legítimas seja muitas vezes considerada o ideal a ser visado, não é perseguida com afinco. O que ocorre constantemente é a concessão parcial dessa espécie de segurança a este ou àquele grupo, do que decorre um aumento constante da insegurança daquelas sobre os quais recai o ônus. Não admitira que, em consequência, aumente também de modo contínuo o valor atribuído ao privilégio da segurança, tornando-se mais e mais premente a sua exigência, até que por fim nenhum preço, nem o da própria liberdade, pareça excessivo.

Uma afirmação semelhante é encontrada em Mises (2010), uma vez que, apesar de suas particularidades, compartilham da mesma defesa neoliberal do fim da intervenção do estado na economia que prejudica o avanço do livre-mercado em prol de melhorias sociais ausentes de um interventor. Em suas considerações, sacrificar as medidas, consideradas por eles, como 
vantagens seria a solução para fugir de um futuro, ou antes presente, Estado totalitário, algo visto como um estímulo ao progresso social, pois, como não se pode pressagiar as formas exatas de oferecer certos bens ou serviços, a liberdade econômica dos agentes é vital para o curso do desenvolvimento. Corroborando na discussão, Mises (2010, p. 105) afirma que

\begin{abstract}
Dar suporte ao desempregado, por meio do governo ou do sindicato, serve apenas para ampliar o mal. Se o que estiver envolvido for o desemprego, causado pelas mudanças dinâmicas da economia, o auxílio-desemprego resultará no adiamento do ajuste dos trabalhadores às novas condições. $\mathrm{O}$ trabalhador desempregado que esteja por isso aliviado não considera necessário procurar uma nova ocupação, se já não encontra emprego em sua antiga ocupação. Pelo menos, deixará correr o tempo, antes que se decida por uma nova ocupação ou localidade, ou antes que ele reduza a taxa de salário que pede por sua qualificação para encontrar trabalho. Se os auxílio-desemprego não forem fixados a um teto muito baixo, pode-se dizer que, na medida em que seja oferecido, o desemprego não desaparecerá.
\end{abstract}

A afirmação supradita não reconhece qualquer forma de organização popular e, portanto, participação nas gestões públicas, o que vai de encontro a gestões democráticas em instituições públicas, como a escola por exemplo, uma vez que não aborda a causa dessa distância entre o povo e o Estado, algo que Paulo Freire realiza em Pedagogia da Autonomia e faz com que compreendamos melhor certos problemas sociais. Freire (2018) não condena a participação ativa da população nas políticas públicas, como faz Mises (2010) e Hayek (2010), mas levanta as causas e possíveis propostas de solução. Freire (2018, p. 57) afirma que

A pedagogia do oprimido, como pedagogia humanista e libertadora, terá dois momentos distintos. O primeiro, em que os oprimidos vão desvelando o mundo da opressão e vão comprometendo-se, na práxis, com a sua transformação; o segundo, em que, transformada a realidade opressora, esta pedagogia deixa de ser do oprimido e passa a ser da pedagogia dos homens em processo de permanente libertação.

A Pedagogia do Oprimido, de Paulo Freire (2018) tem se tornado cada vez mais atual, dada às circunstâncias políticas e a necessidade de suas reflexões. Publicado pela primeira vez em seu exílio em Santiago no Chile no ano de 1968. Em sua obra, Freire (2018) desenvolve uma discussão a respeito da necessidade de uma pedagogia que privilegia a perspectiva do oprimido. O autor dá ênfase à luta pela libertação do indivíduo, pois o mesmo está imerso em sua realidade histórica, mas nem sempre é consciente da mesma.

Na perspectiva Freiriana, torna-se cada vez mais importante compreender o ser humano como um ser inconcluso e que necessita reconhecer a si mesmo para "ser mais", ou seja, superar as limitações impostas pela falta de esclarecimentos das causas da própria realidade. Ele enfatiza a educação baseada no diálogo e na práxis, isto é, reflexão-ação-reflexão. Freire (2018) defende um trabalho sem ser exclusivamente ativista, definido por ele como uma ação sem reflexão, nem fundado na sloganização, a reflexão sem ação, muito menos que se alicerce na 
compreensão do homem como um ser vazio, mas que reconheça os saberes de mundo dos sujeitos. Segundo Freire (2018, p. 72),

O que pode e deve variar, em função das condições históricas, em função do nível de percepção da realidade que tenham os oprimidos, é o conteúdo do diálogo. Substituílo pelo antidiálogo, pelo sloganização, pela verticalidade, pelos comunicados é pretender a libertação dos oprimidos como instrumentos da "domesticação". Pretender a libertação deles sem a sua reflexão no ato desta libertação é transformálos em objeto que se devesse salvar de um incêndio. É fazê-los cair no engodo populista e transformá-los em massa de manobra.

Em contraposição a essa proposta, Paulo Freire (2018) define o que intitula como “educação bancária", nome dado por conta de considerar o aluno uma espécie de recipiente no qual serão depositadas informações em uma relação verticalizada e ausente de diálogos horizontais. Para Freire (2018), a educação bancária é um instrumento de desumanização do sujeito e domesticação do oprimido, visto que o opressor é hospedado em sua consciência como referencial a ser seguido, por isso, o oprimido deseja se tornar opressor, em razão da ausência de acesso a um diálogo horizontal e ausente das marcas da opressão, da invasão cultural camuflada e do que ele compreende como falsa "ad-miração" do mundo. Essa perspectiva reforça a manutenção do status quo de uma elite econômica e na desunião dos oprimidos, já que sua divisão facilita a imposição de políticas destruidoras de direitos conquistados durante décadas, algo visto como concorrência do livre-mercado em prol de uma sociedade na qual os indivíduos irão explorar melhor seus potenciais, contudo, isso levou a manutenção do status quo de um pequeno grupo. Freire (2018), nesse contexto, ressalta a importância do desenvolvimento de uma consciência crítica, para ele

Ter consciência crítica de que é preciso ser o proprietário de seu trabalho e que "este constitui uma parte da pessoa humana" e que a "pessoa humana não pode ser vendida nem vender-se" é dar um passo mais além das soluções paliativas e enganosas. É inscrever-se numa ação de verdadeira transformação da realidade para, humanizandoa, humanizar os homens. (FREIRE, 2018, p. 251). (grifos do autor)

A descrição da noção de trabalho em Paulo Freire (2018) vai além do enfoque na concorrência individual como estímulo ao livre-mercado como defendem os neoliberais clássicos. Hoje, mais de 30 anos depois, a proposta de fazer alguns sacrifícios com a promessa de melhoras permanentes no futuro se tornou utópica, uma vez que as crises são mais frequentes e países onde já existia desigualdade e a concentração de renda apenas se intensificaram em grupos cada vez menores. Assim, temos um crescente avanço do neoliberalismo, atingindo diversas instituições na sociedade, inclusive a escola. Na ótica neoliberal, a atribuição da escola se restringe à transmissão de determinadas competências e habilidades necessárias para que os 
cidadãos possam ser competitivos no mercado, algo para ajudá-los a serem flexíveis em um mercado que exige adaptações diante das conveniências do mercado (LAGOA, 2019, p. 6).

Na compreensão de Paulo Freire (2018), a educação é um ato de humanização e que está presente dentro e fora dos muros da escola, algo que não se faz por imposição, nem na ingenuidade da autossuficiência dos indivíduos, mas através do diálogo e da comunhão de saberes, intermediados pelo mundo no qual vivem, são transformados e transformam, "Mundo que impressiona e desafia a uns e a outros, originando visões ou pontos de vista sobre ele" (FREIRE, 2018, p. 116).

Como ficou patente, são entendimentos distintos do que é educação e a escola como instituições, uma vez que um a compreende como uma instância de preparação para o mundo e o outro como um local a mais de diálogo e conscientização acerca do estar do mundo e até mesmo de transformá-lo.

A tradição pedagógica insiste ainda hoje em limitar o pedagógico à sala de aula, à
relação professor-aluno, educador - educando, ao diálogo singular ou plural entre
duas ou várias pessoas. Não seria esta uma forma de cercear, de limitar a ação
pedagógica? Não estaria a burguesia tentando reduzir certas manifestações do
pensamento das classes emergentes e oprimidas da sociedade a certos momentos,
exercendo sobre a escola um controle não apenas ideológico (hoje menos ostensivo
do que ontem), mas até espacial? Abrir os muros da escola para que ela possa ter
acesso à rua, invadir a cidade, a vida, parece ser ação classificada de "não-pedagógica"
pela pedagogia tradicional. A conscientização sim (até certo ponto), mas dentro da
escola, dentro dos "campi" das Universidades! (FREIRE, 1979, p. 5). (Grifos do
autor)

Indo ao encontro dos princípios freirianos, os ideários defendidos pelo neoliberalismo relacionados à educação do oprimido (FREIRE, 2018) não tem interesse em educar para transformar um mundo que não seja o mundo neoliberal, nem tem como prioridade preparar o sujeito para a cidadania, já que a demanda das empresas está à frente dessas questões.

A transformação da Educação em treinamento, coloca em evidência o próprio debate
sobre o que tais concepções entendem por conhecimento. Essas teorias pedagógicas,
sendo o construtivismo a mais influente nas últimas décadas, e que se tornou o carro
chefe para várias outras pedagogias do aprender a aprender - teoria do professor
reflexivo, pedagogia dos projetos, das competências, do multiculturalismo, etc. - têm
como centralidade a limitação do conhecimento a uma função adaptativa. Quer dizer,
tem como fundamento uma teoria do (des)conhecimento que não se refere a realidade
ontológica e objetiva, em seu lugar apresenta uma forma pragmática de conhecimento
que se limita à compreensão do ordenamento e a organização de um mundo
constituído pelas experiências individuais (LAGOA, 2019, p. 8).

É válido ressaltar que o mesmo grupo intelectual que argumenta essa necessidade única da educação é favorável a um exército industrial de reserva para atender à demanda das 
empresas. Também são os mesmos que descrevem os direitos conquistados pela classe trabalhadora para atender às exigências das empresas.

No regime de concorrência, as probabilidades de um homem pobre conquistar grande
fortuna são muito menores que as daquele que herdou sua riqueza. Nele, porém, tal
coisa é possível, visto ser o sistema de concorrência o único em que o enriquecimento
depende exclusivamente do indivíduo e não do favor dos poderosos, e em que
ninguém pode impedir que alguém tente alcançar esse resultado. Já esquecemos o que
significa a falta de liberdade; essa é a razão pela qual muitas vezes não percebemos o
fato evidente de que em todos os sentidos, um trabalhador não-especializado e mal
pago tem, na Inglaterra mais liberdade para escolher o rumo da sua ida do que muitos
pequenos empresários na Alemanha, ou do que engenha ou gerente de empresa muito
mais bem pago na Rússia. (HAYEK, 2010, p. 114).

Essa afirmação de Hayek (2010) é incompatível com os resultados que o neoliberalismo cada vez mais crescente tem apresentado, a omissão da concorrência desleal em nosso sistema de educação é claramente detalhada por Freire (2018). Após falar da importância de uma pedagogia sob o ponto de vista do oprimido, definir a concepção bancária de educação e defender a importância do diálogo na relação professor-aluno. Em Pedagogia do Oprimido, Freire (2018) conclui o livro realizando uma crítica a ação antidialógica, focada no interesse de conquistar do que partilhar, dividir as massas populares na promessa de uma livre concorrência para manter uma opressão latente e ao mesmo tempo permitindo que uma invasão cultural e manipulação ideológica desqualifica a identidade cultural de um povo. Por fim, faz um convite para a união, se o neoliberalismo defende a concorrência em prol da liberdade. Freire (2018) postula exatamente o contrário, que a união leva à libertação, pois tem o indivíduo como um ator e também sujeito no processo histórico, portanto, nada está definido, imutável nem dado, as formatações sociais estão em aberto a depender das reflexões e ações dos sujeitos.

A brevidade da presente seção não é suficiente para abordar a gama de pontos levantados pelas obras de Hayek (2010) e Freire (2018), contudo, demos enfoque aos tópicos que aproximam da delimitação do presente artigo; o conceito de liberdade em duas óticas distintas, mas em contextos semelhantes, uma vez que Paulo Freire escreveu a Pedagogia do Oprimido quando o neoliberalismo começou a ascender em escala intercontinental. Nesta seção, a ideia de liberdade superficialmente abordada no decorrer da explanação das duas obras, mas é necessária uma discussão exclusiva sobre esse conceito, para assimilar melhor a distinção radical entre o que se compreende por liberdade no pensamento de um autor que escreveu sob a ótica do oprimido e de outro a partir do ponto de vista de grupos privilegiados. 


\section{$4 O$ conceito de liberdade neoliberal $X$ a liberdade freiriana}

A compreensão de liberdade em Hayek (2010) teve atenção particular no capítulo 9, "Segurança e liberdade" do seu livro "O caminho da Servidão". Ele inicia abordando que a ideia de segurança econômica é vaga e ambígua, assim como outros conceitos nesse campo. Partindo desse pressuposto, o autor conclui que a reinvindicação de segurança é um perigo para a liberdade. Afirma que em vez de permitir maior liberdade, ela a restringe (HAYEK, 2010).

Em um contexto de polarização de guerra fria, uma citação de Lênin (1917) e outra de Leon Trotsky (1937), sem esclarecer em qual contextualização se encontram, deixa claro o alvo das críticas; "Num país em que o único empregador é o Estado, oposição significa morte lenta por inanição. O velho princípio 'quem não trabalha não come' foi substituído por outro: ‘quem não obedece não come'. - Leon Trotsky (1937)" (HAYEK, 2010, p. 126). Essas afirmações com esse nível de violência deixam claro que, no entender do autor, o Estado ceifa a liberdade econômica em nome de uma segurança que não dá mais liberdade, mas a qual liberdade se refere?

Antes disso, Hayek (2010) define dois tipos de segurança; a segurança limitada, ou seja, a privação contra certos confortos, um que compreende como uma qualidade mínima de sustento que deve ser garantida. A outra se refere à segurança absoluta, o que para o autor, diferente da outra, não pode ser de todos, pois garante um padrão de vida a um determinado grupo minoritário em detrimento de uma maioria, curioso que ele define o que se entende por elite sem expor o termo.

Em seguida, Hayek (2010) declara que nossa sociedade já conquistou esse mínimo de conforto para a população, pois em sua reflexão; "não há dúvida de que, no tocante a alimentação, roupas e habitação, é possível garantir a todos um mínimo suficiente para conservar a saúde e a capacidade do trabalho" (HAYEK, 2010, p. 128). O autor vai aos poucos detalhando quais pontos devem ser mudados para chegar a nível idealizado de concorrência: "sob o nome de previdência social, é possível introduzir medidas que contribuirão para tornar a concorrência bastante ineficaz" (HAYEK, 2010, p. 128). Se por um lado ele afirma que não há incompatibilidade no fato do estado trazer mais segurança com um sistema de previdência social e a garantia da liberdade individual, por outro; 
Contudo, para que a escolha das ocupações seja livre, as garantias de uma determinada renda não pode ser concedida a todos. E se for concedida a alguns privilegiados, haverá prejuízo para outros, cuja segurança será, ipso facto ${ }^{2}$, diminuída. É fácil demonstrar que a garantia de uma renda invariável só poderá ser concedida a todos pela abolição total da liberdade de escolha da profissão. E contudo, embora essa garantia geral de expectativas legítimas seja muitas vezes considerada o ideal a ser visado, não é perseguida com afinco. O que ocorre constantemente é a concessão parcial dessa espécie de segurança a este ou àquele grupo, do que decorre um aumento constante da insegurança daqueles sobre os quais recai o ônus. Não admira que, em consequência, aumente também de modo contínuo o valor atribuído ao privilégio da segurança, tornando-se mais e mais premente a sua exigência, até que por fim nenhum preço, nem o da própria liberdade, pareça excessivo. (HAYEK, 2010, p. 130).

No decorrer de sua argumentação, a defesa da escolha de uma profissão e de um poder aquisitivo que dê determinada qualidade de vida gira em torno da ideia de liberdade defendida pelo autor. Conquanto, já exposto na seção anterior, Hayek (2010) e outros pensadores neoliberais, como Mises (2010), defendem a polivalência da população para se adequar ao mercado de trabalho, isso parece uma contradição, pois se o indivíduo precisa se adequar ao livre-mercado, a liberdade é do mercado e não sua.

Frigotto $\left(2002\right.$, p.83) afirma que a tese de Hayek $(2010)^{3}$ é "a de que o princípio e a busca da igualdade social levam à servidão. Não é casual que esta tese, defendida no início dos anos 40, seja hoje a base teórico-ideológica do neoliberalismo", contudo, contrapondo-se à Hayek (2010), Frigotto (2002, p. 83) afirma ser uma falácia a livre concorrência numa sociedade de classes, uma vez que a história tem demonstrado uma desigualdade chocante, tanto entre nações como dentro de cada uma, pondo até mesmo o capitalismo em risco. A crise na década de 1930 foi superada através de uma forte intervenção do Estado na sociedade e na economia.

Com o neoliberalismo em alta e a tese do Estado mínimo, muitas conquistas sociais desconsideradas, assim, o direito à saúde, educação, estabilidade de emprego, transportes públicos, tornam-se regidas por leis do mercado aparentemente não controladas por uma instituição estatal que atende às necessidades individuais, nada obstante, "a ideia de Estado mínimo significa o Estado suficiente e necessário unicamente para os interesses da reprodução do capital" (FRIGOTTO, 2002, p. 84). Em suas aplicações, as ideias neoliberais tem se apresentado como um caminho para a legitimação da exclusão social. Segundo Frigotto (2002, p. 84),

\footnotetext{
2 Termo latino, significa "pelo próprio fato".

${ }^{3}$ Ressaltamos que 2010 é o ano de publicação da edição da obra a qual tivemos acesso, sendo a primeira edição do livro lançada em 1944.
} 
O dado mais perverso, neste plano, é o processo de naturalização da exclusão, das diferentes formas de violência, inclusive o puro e simples extermínio de grupos e populações. São indícios claros deste malthusianismo anacrônico: as frias análises custo-benefício da poluição, feitas por técnicos do Banco Mundial que, ao constatarem os custos da mesma serem até cinco vezes maior nos países desenvolvidos, recomendam despoluí-los enviando o lixo industrial para os países onde cada morte tem um custo menor; as pregações de dirigentes do Fundo Monetário Internacional que, face ao colapso econômico do México, afirmam que os investidores internacionais somente voltarão a ter confiança para novamente investir naquele país se o governo exterminar os rebeldes de Chiapas; na mesma lógica, encontramos as justificativas do apressamento da morte ou simples e puro não atendimento de crianças pobres e subnutridas porque há falta de aparelhos remédios, etc., e, por isso, a atenção deve ser dada às crianças cujas chances de cura são mais elevadas.

Essa liberdade também é contraditória, uma vez que fala de um padrão de vida que não é mundial, mas setorial. Walter Rodney (1975), em Como a Europa subdesenvolveu a África, fala das ideias de desenvolvimento e subdesenvolvimento, ambos ocorrendo paralelamente em continentes distintos, mas com uma relação dialética. A Europa Ocidental estabeleceu com a África uma relação econômica que permitiu a transferência de riquezas desta para aquela, algo possível após a internacionalização do comércio nos fins do século XV, quando também a Ásia e as Américas também dialogaram economicamente com a Europa e a África, uma vez que imigrantes forçados da África foram para outros continentes além do europeu. Essa relação durou cinco séculos e permitiu que a Inglaterra acumulasse capital suficiente para iniciar no fim do século XVIII o que chamamos de Revolução Industrial (RODNEY, 1975). Como vemos, o público alvo da sua obra tinha um padrão de vida avançado se comparar a outros países, ao passo que em nenhum momento Hayek (2010) esclarece a maneira como esse padrão foi conquistado, uma vez que generaliza um contexto Europeu e Norte-Americano na época.

Na obra Pedagogia do Oprimido (2018), o título evidencia os protagonistas da mesma. Freire (2018) fala da falta de consciência histórica que impossibilita o indivíduo de conhecer a si mesmo e o lugar que ocupa no mundo, "o que pode e deve variar, em função das condições históricas, em função do nível de percepção da realidade que tenham os oprimidos, é o conteúdo do diálogo" (FREIRE, 2018, p. 72). O autor enfatiza que "Ninguém liberta ninguém, ninguém se liberta sozinho: os homens se libertam em comunhão" (FREIRE, 2018, p. 75), uma perspectiva contrária à da concorrência livre e individual, algo que Paulo Freire (2018) denuncia como um discurso que enfraquece o poder de reivindicação das massas, através da práxis que integra ação e reflexão. 
Em Freire, o reconhecimento da diferença como riqueza da humanidade é combinado com o que ele chama de ética universal do ser humano. A identificação do que seja a dignidade tem a ver com o contexto específico, mas também com uma compreensão do pertencimento a uma mesma espécie planetária. As condições de diferenciação entre os ricos pelo rótulo do vinho e outras sofisticações têm a ver com a indignidade da fome em países do Terceiro Mundo. A partir daí também se dá o inescapável encontro do ético com o político. É, no entanto, uma sinalização de que a conquista de espaços e de poder, em si, não é condição suficiente para a transformação da sociedade. (STRECK, 2009, p. 553).

Na Pedagogia do Oprimido, os oprimidos e oprimidas possuem uma grande empreitada; libertar não apenas a si, mas também aos opressores e opressoras. Ele justifica isso na defesa de que os opressores não os libertarão, uma vez que o poder destes desumaniza todo o conjunto da sociedade, apesar de todo o poder construído ser dependente dos próprios oprimidos.

Contudo, a liberdade não é definida por Freire (2018) como um fenômeno dado por mãos invisíveis, como defende o neoliberalismo com os mecanismos do mercado econômico, mas através da recuperação da humanidade, suprimida por meio da opressão, segundo ele: “A liberdade, que é uma conquista, não uma doação, exige uma permanente busca. Busca permanente que só existe no ato responsável de quem a faz" (FREIRE, 2018, p. 46), pois se ninguém possui de maneira inata a dádiva de ser livre, caso possuíssem não faria sentido lutar pela liberdade. Paulo Freire defende a liberdade como um processo a ser conquistado com conscientização e ação, diferente do neoliberalismo que defende o poder libertador do mercado econômico desde Hayek (2010), mas a desigualdade social e logicamente a privação de liberdade têm sido cada vez mais assustadoras. Essa situação já comprovada é explicada pelo que Freire (2018) definiu como uma inclusão do oprimido na consciência opressora, o que não contribui para a libertação dos oprimidos, mas para o surgimento de novos opressores que irão subjugar um número cada vez maior de pessoas oprimidas.

\section{Conclusões}

$\mathrm{O}$ artigo tendo por objetivo discutir os contrapontos entre o discurso neoconservador construído historicamente e os princípios defendidos por Freire (2018) sobre liberdade e de formação humana, em linhas gerais, mostra que Freire (2018, p. 72) defende o reconhecimento do potencial dos oprimidos, "Que os vejamos como capazes de pensar certo também”. Esse pensamento se coloca contrário ao neoliberal, uma vez que não oferece espaço para os indivíduos serem sujeitos da história, alteradores da realidade, mas participantes de uma realidade dada.

As discussões ao longo do artigo evidenciam que Freire (2018) abordou pontos inexplorados por Hayek (2010), como as riquezas da pluralidade humana em seus potenciais 
como indivíduos humanizados e não pelo capital que acumulam. Nesse sentido, a escola como mais um espaço possível para ocorrer à educação humanizadora deve ser plural também em seu currículo, ao contrário, não irá garantir a valorização da diversidade humana, principalmente em um país como o Brasil, mas a formação de um contingente qualificado como mão-de-obra para as empresas como prioridade, o que reduz radicalmente o conceito de educação em termos freirianos, focando em adaptá-lo a uma realidade construída, mas não conscientizá-lo do seu potencial de poder mudar essa realidade, o que demonstra um caráter doutrinário da concepção neoliberal de escola como instância e educação como conceito.

A educação escolar, no contexto neoliberal, é vista apenas como uma preparação para o mercado de trabalho. Nesse sentido, teremos uma instituição que deixa as discussões acerca da cidadania, da convivência e do diálogo nas mãos de outros espaços, muitas vezes, sem tais objetivos, como as empresas, igrejas e a grande mídia, portanto, reduz a liberdade do indivíduo se autorreconhecer em meio à diversidade na qual está imerso. Essa perspectiva neoliberal reforça ainda mais a atualidade do pensamento de Paulo Freire pela luta da libertação do oprimido.

Em últimas palavras, Hayek (2010) fala que a segurança dada através de intervenções do estado se torna uma insegurança, uma vez que há contraste entre a segurança dos privilegiados e a dos favorecidos. No entanto, não detalhou quem seriam os privilegiados nesse caso, uma vez que o texto subtende o auxílio às vulnerabilidades sociais como um privilégio, uma vez que, segundo ele, "A maioria das pessoas necessita, em geral, de alguma pressão externa para se esforçar ao máximo" (HAYEK, 2010, p. 131), adiante considera: "E quanto mais segurança se converte num privilégio, e quanto maior o perigo para os que dela são excluídos, mais será ela valorizada" (HAYEK, 2010, p. 135). Assim, Hayek (2010) defende que enquanto aumenta o número de pessoas beneficiadas pelo Estado com direitos conquistado após muitas tensões sociais, o que compreende como privilégios, surge um hiato entre eles e a insegurança dos não beneficiados. E conclui que a distinção e status não é mais assegurada pela independência, mas pela segurança, mais uma vez o conceito de liberdade é restrito ao capital acumulado pelo indivíduo.

Em oposição ao pensamento neoliberal, Freire (2018) defende a liberdade como algo a ser conquistado pelos oprimidos, ou seja, a grande maioria da população, processo que se dá através de uma educação que vai além dos muros da escola e de uma escola que pode ir também além dos seus muros, ao contrário, a educação que apenas prepara os indivíduos para competir entre si sem uma conscientização do seu estar no mundo, apenas os instrui para conhecerem a ideologia dos seus opressores, o que irá colaborar para que alguns deles se tornem também 
opressores e oprimam um contingente cada vez maior de oprimidos, algo já comprovado segundo as estatísticas a respeito da desigualdade.

Em últimas palavras, a liberdade em Freire (2018) demonstra mais coerência, já que a liberdade neoliberal não produz liberdade para uma maioria, mas prepara contingentes de trabalhadores sem uma prioridade de erradicar o desemprego, mas de gerar cada vez mais lucro para um número menor de pessoas, uma vez que a geração de oprimidos pensando como opressores tem gerado cada vez mais opressão.

\section{Referências}

ARENDT, Hannah. As origens do totalitarismo. São Paulo. Companhia das Letras, 1989.

CELESTINO JÚNIOR. "A ideologia da incompetência do outro e outras ideologias de conveniência na relação neoliberalismo e educação". In: GHIRALDELLI JUNIOR, Paulo (Org.). Infância, Educação e Neoliberalismo. São Paulo: Cortez, 1996 (Coleção questões da nossa época, v. 61)

CERQUEIRA, Jackson B. A. de. Uma visão do neoliberalismo: surgimento, atuação e perspectivas. In: Sitientibus, Feira de Santana, n.39, p. 169-189, jul./dez. 2008.

CERTEAU, Michel. A invenção do cotidiano: artes de fazer. $3^{\circ}$ ed. Petrópolis. Editora Vozes, 1998.

FREIRE, Paulo. Ação cultural para a liberdade. $5^{\circ}$ ed. Rio de Janeiro. Paz e Terra, 1981.

FREIRE, Paulo. Educação e mudança. 12º ed. Rio de Janeiro. Paz e Terra, 1979.

FREIRE, Paulo. Pedagogia do oprimido. 65 ed. Rio de Janeiro/São Paulo. Paz e Terra, 2018.

FRIGOTTO, Gaudêncio. Crise do capital e metamorfose conceitual no campo educacional. In: GENTILI, Pablo. Pedagogia da exclusão: crítica ao neoliberalismo em educação.

Petrópolis. Editora Vozes, 2002.

GENTILI, Pablo. A Falsificação do Consenso - simulacro e imposição na reforma educacional do neoliberalismo. Petrópolis, Rio de Janeiro: Vozes, 1998.

HARVEY, David. O neoliberalismo: história e implicações. Tradução: Adail Sobral/ Maria Stela Gonçalves. São Paulo. Edições Loyola, 2008.

HAYEK, Friedrich August Von. O caminho da servidão. São Paulo. Instituto Ludwing von Mises Brasil, 2010.

LAGOA, Maria Izabel. A ofensiva neoliberal e o pensamento reacionário-conservador na política educacional brasileira. Rev. HISTERBR On line. Campinas-SP, v. 19, p. 1-14, 2019. 
MATOS, Sidney Tanaka S. Conceitos primeiros de neoliberalismo. In: Mediações. v. 13, n. 1-2, p. 192-213, Jan/Jun e Jul/Dez. 2008.

MISES, Ludwig von. Liberalismo - segundo a tradição clássica. São Paulo. Instituto Ludwig von Mises Brasil, 2010.

RODNEY, Walter. Como a Europa subdesenvolveu a África. Lisboa. Seara Nova, 1975.

STRECK, Danilo Romeu. Da pedagogia do oprimido às pedagogias da exclusão: um breve balanço crítico. Educ. Soc., Campinas, vol. 30, n. 107, p. 539-560, maio/ago. 2009.

TORRES, Carlos Alberto. Estado, Privatização e Política educacional - elementos para uma crítica do neoliberalismo. In: GENTILI, Pablo (Org.). Pedagogia da exclusão - crítica ao neoliberalismo em educação. Petrópolis: Vozes, 1995.

VILLARREAL, Rene. A contra-revolução monetarista: Teoria política e ideologia do neoliberalismo. Rio de Janeiro: Record, 1984. 